\title{
Dynamic simulation applied to refinery hydrogen networks
}

\author{
Aníbal Galán \\ Departamento de Ingeniería de Sistemas y Automática, Universidad de Valladolid, Calle Real de \\ Burgos, Sede Mergelina - EII, Valladolid, 47011, anibalsantiago.galan@uva.es \\ César De Prada \\ Departamento de Ingeniería de Sistemas y Automática, Universidad de Valladolid, Calle Real de \\ Burgos, Sede Mergelina - EII, Valladolid, 47011, prada@autom.uva.es \\ Gloria Gutierrez \\ Departamento de Ingeniería de Sistemas y Automática, Universidad de Valladolid, Calle Real de \\ Burgos, Sede Mergelina - EII, Valladolid, 47011, gloria@autom.uva.es
}

Daniel Sarabia

Departamento de Ingeniería Electromecánica, Escuela Politécnica Superior, Universidad de Burgos, Avda. Cantabria s/n, Burgos, 09006, dsarabia@ubu.es

Rafael González

Petroleos del Norte, S.A, Petronor, Muskiz 48550, rgonzalezm@repsol.com

\begin{abstract}
This study analyses the usefulness of process network dynamics simulation for decision-making in refinery hydrogen networks. A theoretical hydrogen network of three desulphurisation plants is modelled, and three case scenarios discussed: baseline, high demand, and low demand.

Discussion focuses on how the information from the simulation is interpreted and its usefulness for debottlenecking, scheduling and what-if analysis. Stress is put on dynamics of the system and their consequences in process operation throughout the network. Hydrogen purity is highlighted as the most affected variable, and discussed its network wide effect. In addition, the responses of inflows, outflows and headers are analysed.

Although the model used is a simplified representation of the actual processes, the simulation analysis showed potential as decision-making support not provided with steady state models. Further researches based on real case-studies should be conducted to better conclude on the efficient usage of simulation in aiding refinery hydrogen networks operational decisions.
\end{abstract}

Keywords: network simulation, process dynamics, decision-making.

\section{INTRODUCTION}

Hydrogen $\left(\mathrm{H}_{2}\right)$ is an essential utility in refineries, due to its use as reactant in desulphurisation process units. Furthermore, environmental regulations limit sulphur content in fuels forcing refineries to produce low sulphur fuels [2, 5, 11-12].

Although less than $10 \%$ of the time process units are under transition states, most of the operational deviations, including process safety issues occur then [3]. Hence, simulation of transitions is of key importance in process networks in general and $\mathrm{H}_{2}$ networks in particular. Interest in the study of transient conditions could minimise the overlooking of process safety. It could lead to unexpected scheduling bottlenecks, for example by delaying on specification products. Other negative effects due to variable $\mathrm{H}_{2}$ purity could be: high purge rates, reduced catalyst lifecycle and increased rotating machineries malfunction. Simulation can be used for analysis of scenarios, supporting decisions at different levels of operation, aiding in the decision-making process. In fact, increased focus on dynamic modelling and simulation of transition states is seen [1-3, 15]. For instance, in scheduling, process debottlenecking, what-if analysis, flowsheet design, being most of them simulations combined with optimisation $[1,3$, 5-8, 10-11, 14-16].

Refinery $\mathrm{H}_{2}$ networks main components are: gas headers (e.g.: high purity header - HPH -, low purity header - LPH - and fuel gas header - FGH -), hydrotreating plants and their components (e.g.: hydrodesulphurisation plant - HDS -), and $\mathrm{H}_{2}$ source (e.g.: typically a steam reforming unit). In Figure 1 the arrangement of the network considered in this work is shown. Basically, the network has a $\mathrm{H}_{2}$ source that serves the consumer plants. However, $\mathrm{H}_{2}$ should be well in excess to minimise catalyst early decay and suffice compressors safe operation region. 
Therefore, reactors outflows are recycled through recycle compressors and consumed gas is fed to comply with units' pressure control. A typical desulphurisation plant is shown in Figure 2.

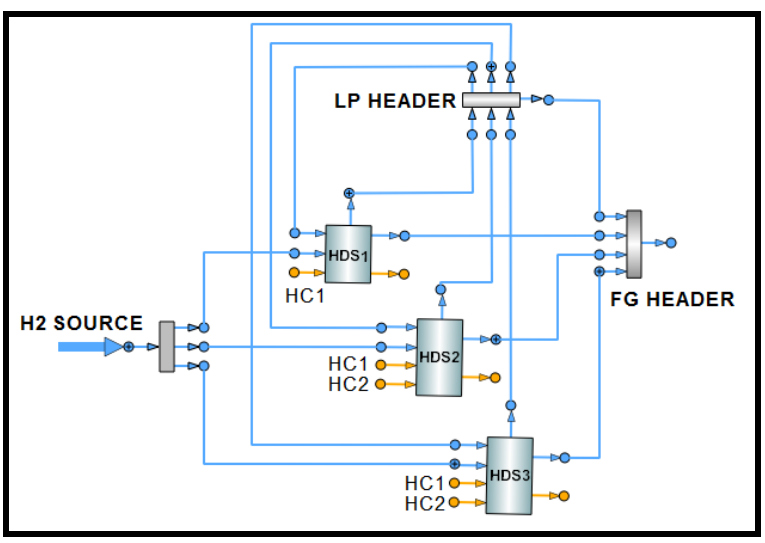

Figure 1: Network topology.

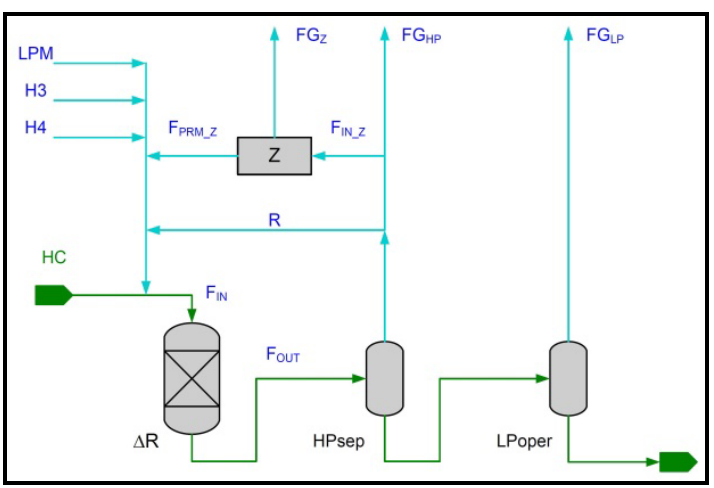

Figure 2: Schematic of a representative hydrotreating unit [5].

This work aims at studying the usefulness of simulation for decision support of refinery hydrogen $\left(\mathrm{H}_{2}\right)$ networks during transition states incorporating simplified process dynamics. This is approached through studying three case scenarios of a representative theoretical network with different process condition transitions. Then discussing which are the main variables and how are they affected. Additionally, the main limitations of this methodology are pointed out, as well as some ideas of future research on this topic.

\section{METHODOLOGY}

\subsection{NETWORK TOPOLOGY}

A hypothetical network flowsheet was modelled (see Figure 1), comprising the components listed in Table 1. These components were modelled using first principles and specific mass and chemical equations where applicable (i.e.: reactors and separation drums).

Table 1: Network components modelled. *Components coded within each HDS. ${ }^{* *}$ Only in HDS3.

\begin{tabular}{|l|l|}
\hline$\#$ & Component \\
\hline 1 & $\mathrm{H}_{2}$ source (HP) \\
\hline 1 & HP make-up header (HPMU) \\
\hline 1 & LPH (Low Purity Header) \\
\hline 1 & FGH (Fuel Gas Header) \\
\hline 3 & HDS $1 / 2 / 3^{*}{ }^{*}$ \\
\hline 3 & Reactor (R1) \\
\hline 3 & HP drum (SHP) $^{*}$ \\
\hline 3 & LP drum (SLP) $^{*}$ \\
\hline 3 & Amine column (ACL) $^{*}$ \\
\hline 3 & Recycle compressor (RC) $^{*}$ \\
\hline 1 & Make-up compressor (C_MU) $^{*}$ \\
\hline
\end{tabular}

Flow diagrams of the HDSs modelled are shown in Figure 3.

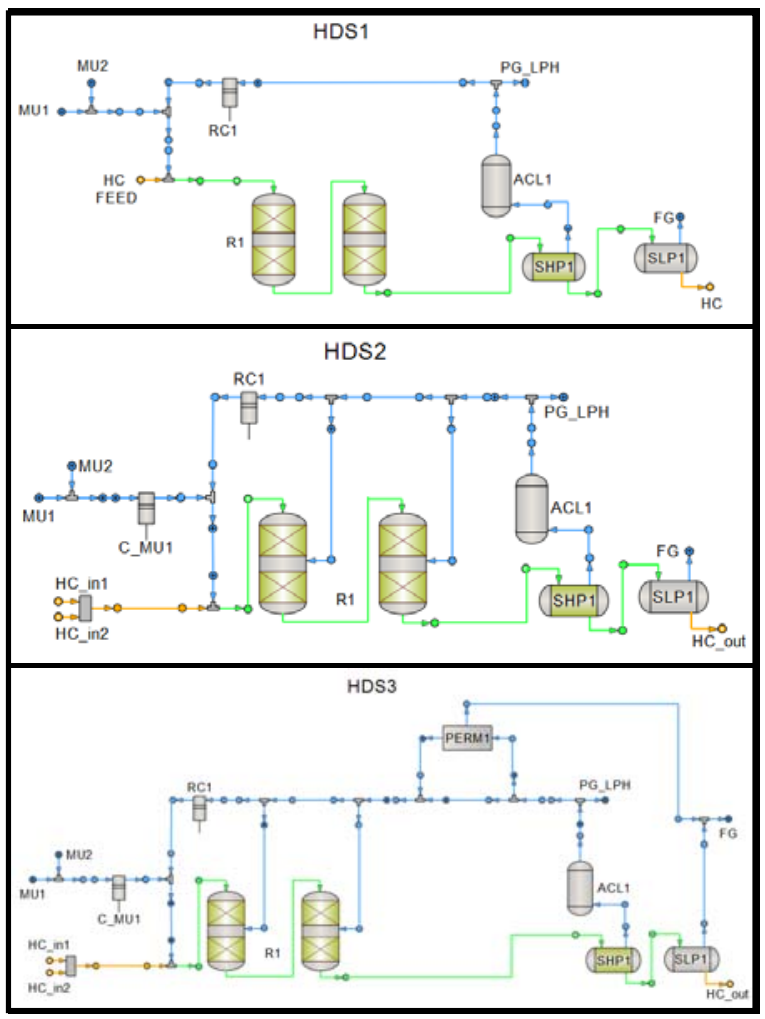

Figure 3: Flow diagram of HDSs 1-3.

\subsection{MATHEMATICAL MODEL}

Equations used are basically mass and gaseous component balances. In fact, both represented with the general form shown in equations 1-2, meaning that input equals output (except in reactors). 


$$
\begin{gathered}
\Sigma \mathrm{F}_{\text {IN }}=\Sigma \mathrm{F}_{\text {OUT }} \\
\left.\Sigma\left(\mathrm{F}_{\text {IN }} \text { x y }\left[\mathrm{H}_{2}\right]_{\text {IN }}\right)=\Sigma\left(\mathrm{F}_{\text {OUT }} \text { x y[ } \mathrm{H}_{2}\right]_{\text {oUT }}\right)
\end{gathered}
$$

Where: $\mathrm{F}$ is the volumetric flow (IN / OUT of the system), $\mathrm{y}\left[\mathrm{H}_{2}\right]$ is the molar fraction of $\mathrm{H}_{2}$ (IN / OUT of the system)

In reactors, $\mathrm{H}_{2}$ consumption $\left(\mathrm{H} 2_{\mathrm{CON}}\right)$ and $\mathrm{LIG}$ generation $\left(\mathrm{LIG}_{\mathrm{GEN}}\right)$ are calculated proportional to $\mathrm{HC}$ (see equations 3-4, where: $\mathrm{k}_{\mathrm{LIGHC}}$ and $\mathrm{k}_{\mathrm{H} 2 \mathrm{HC}}$ are the first order reaction constants). In addition, four terms were considered to account for $\mathrm{H}_{2}$ consumption and LIG generation with their corresponding effect on mass balances, see equations 5-8. Where: $\mathrm{H} 2{ }_{\mathrm{CON}}$ and $\mathrm{LIG}_{\mathrm{GEN}}$ are $\mathrm{H}_{2}$ consumed and light ends generated through reactions, $\mathrm{G}$ is the $\mathrm{HC}$ liquid flow (IN / OUT of the system), $\mathrm{LIG}_{\mathrm{MW}}$ is the molecular weight of LIGsand

$$
\begin{array}{r}
\mathrm{H} 2_{\mathrm{CON}}=\mathrm{k}_{\mathrm{H} 2 \mathrm{HC}} \times \mathrm{HC}_{\mathrm{IN}} \\
\mathrm{LIG}_{\mathrm{GEN}}=\mathrm{k}_{\mathrm{LIGHC}} \times \mathrm{HC}_{\mathrm{IN}} \\
\Sigma \mathrm{F}_{\mathrm{IN}}-\mathrm{H} 2_{\mathrm{CON}}+\mathrm{LIG}_{\mathrm{GEN}}=\Sigma \mathrm{F}_{\mathrm{OUT}} \\
\Sigma\left(\mathrm{F}_{\mathrm{IN}} \times \mathrm{y}\left[\mathrm{H}_{2}\right]_{\mathrm{IN}}\right)-\mathrm{H} 2_{\mathrm{CON}}=\Sigma\left(\mathrm{F}_{\mathrm{OUT}} \times \mathrm{y}\left[\mathrm{H}_{2}\right]_{\mathrm{OUT}}\right) \\
\Sigma \mathrm{G}_{\mathrm{IN}}-\mathrm{LIG}_{\mathrm{GEN}} \times \mathrm{LIG}_{\mathrm{MW}}=\Sigma \mathrm{G}_{\mathrm{OUT}} \\
\Sigma\left(\mathrm{F}_{\mathrm{IN}} \times \mathrm{y}[\mathrm{LIG}]_{\mathrm{IN}}\right)-\mathrm{LIG}_{\mathrm{GEN}}=\Sigma\left(\mathrm{F}_{\mathrm{OUT}} \times \mathrm{y}[\mathrm{LIG}]_{\mathrm{OUT}}\right)
\end{array}
$$

Separation drums (HP/LP drums) have specific additional equations (9-10) that represent how they split their mixed gas and liquid inlet $\left(\mathrm{G}_{\mathrm{IN}}\right)$ streams into a gas outlet $\left(\mathrm{F}_{\mathrm{OUT}}\right)$ and mixed gas and liquid outlet $\left(\mathrm{G}_{\text {OUT }}\right)$. The latter containing the gases that remain solubilised from the $\mathrm{G}_{\mathrm{IN}}$. A solubility constant for: gas in $\mathrm{HC}$ and $\mathrm{H}_{2}$ in $\mathrm{HC}$, should be considered for this behaviour to be useful $[6,13]$. In the particular case of LP drums $\mathrm{G}_{\text {OUT }}$ is free of gases.

$$
\begin{gathered}
\mathrm{Gas}_{\mathrm{L}}=\mathrm{k}_{\mathrm{GHC}}^{\mathrm{s}} \times \mathrm{HC}_{\mathrm{IN}} \\
\mathrm{G}_{\text {OUT }} \times \mathrm{y}\left[\mathrm{H}_{2}\right]_{\text {OUT }}=\mathrm{k}_{\mathrm{H} 2 \mathrm{HC}}^{\mathrm{s}} \times \mathrm{HC}_{\mathrm{IN}}
\end{gathered}
$$

Where $\mathrm{k}_{\mathrm{GHC}}^{\mathrm{s}}$ and $\mathrm{k}_{\mathrm{H} 2 \mathrm{HC}}^{\mathrm{s}}$ are the solubilities of gas and $\mathrm{H}_{2}$ in $\mathrm{HC}$ respectively, $\mathrm{HC}_{\mathrm{IN}}$ is the $\mathrm{HC}$ inlet to the drum.

Rather than applying a rigorous model to represent chemical consumption and generation of gases, a simplified empirical first order dynamic is imposed. The same simplification is used to account for solubility dynamics $\left(\mathrm{k}_{\mathrm{H} 2 \mathrm{HC}}^{\mathrm{s}}, \mathrm{k}_{\mathrm{GHC}}^{\mathrm{s}}\right)$. Therefore, changes in coefficients $\mathrm{k}_{\mathrm{GHC}}^{\mathrm{s}}, \mathrm{k}_{\mathrm{H} 2 \mathrm{HC}}^{\mathrm{s}}, \mathrm{k}_{\mathrm{H} 2 \mathrm{HC}}$ and $\mathrm{k}_{\text {LIGHC}}$, are modelled using equation 11 that represents the generic form of them all. Time constants $\left(\tau_{\mathrm{i}}\right)$ used were: $0.45 \mathrm{~h}\left(\tau_{\mathrm{R} 1}\right)$ and $0.65 \mathrm{~h}$ $\left(\tau_{\mathrm{SHP}}\right)$, for reactions and separators respectively. These values were deemed sensible for typical HDS processes reaching steady state after $2 \mathrm{~h}$ in reactors and $3 \mathrm{~h}$ in separation drums [12-13]. One hour delay is included between reactors and downstream drums to account for fluid hydraulic time.

$$
\mathrm{Y}(\mathrm{t})+\tau_{\mathrm{i}} \mathrm{x} \mathrm{Y}(\mathrm{t})^{\prime}=\mathrm{k}
$$

Where: $\mathrm{Y}$ is a derivable function of time $(\mathrm{t})$ with value $\mathrm{k}$ at $\mathrm{t}=\infty$, and first derivative $\mathrm{Y}$ '. Therefore: $\mathrm{k}_{\mathrm{GHC}}^{\mathrm{s}}, \mathrm{k}_{\mathrm{H} 2 \mathrm{HC}}^{\mathrm{s}}, \mathrm{k}_{\mathrm{H} 2 \mathrm{HC}}$ and $\mathrm{k}_{\mathrm{LIGHC}}$ were represented as time dependent coefficients with known steady state values. Transitions were computed applying equation 11 with $\tau_{\mathrm{R} 1}=0.45 \mathrm{~h}, \tau_{\mathrm{SHP}}=0.65 \mathrm{~h}$.

General statistics of the system from PROSIS ${ }^{\circledR}$ [4]

\begin{tabular}{|c|c|c|c|c|}
\hline & \multicolumn{4}{|c|}{ Case 1: Baseline } \\
\hline & $\mathrm{k}_{\mathrm{H} 2 \mathrm{HC}}$ & $\mathrm{k}_{\mathrm{LIGHC}}$ & $\mathrm{k}_{\mathrm{GHC}}^{\mathrm{s}}$ & $\mathrm{k}_{\mathrm{H} 2 \mathrm{HC}}^{\mathrm{s}}$ \\
\hline & $\mathrm{Nm}^{3} / \mathrm{m}^{3}$ & $\mathrm{Nm}^{3} / \mathrm{m}^{3}$ & $\mathrm{Nm}^{3} / \mathrm{m}^{3}$ & $\mathrm{Nm}^{3} / \mathrm{m}^{\mathrm{m}}$ \\
\hline HDS1 & 30 & 1.5 & 10 & 6 \\
\hline HDS2 & 60 & 5 & 13 & 14 \\
\hline \multirow[t]{4}{*}{ HDS3 } & 70 & 6 & 14 & 8 \\
\hline & \multicolumn{4}{|c|}{ Case 2: High $\mathrm{H}_{2}$ demand } \\
\hline & $\mathrm{k}_{\mathrm{H} 2 \mathrm{HC}}$ & $\mathrm{k}_{\mathrm{LIGHC}}$ & $\mathrm{k}_{\mathrm{GHC}}^{\mathrm{s}}$ & $\mathrm{k}_{\mathrm{H} 2 \mathrm{HC}}^{\mathrm{s}}$ \\
\hline & $\mathrm{Nm}^{3} / \mathrm{m}^{3}$ & $\mathrm{Nm}^{3} / \mathrm{m}^{3}$ & $\mathrm{Nm}^{3} / \mathrm{m}^{3}$ & $\mathrm{Nm}^{3} \mathrm{~m}^{\mathrm{m}}$ \\
\hline HDS1 & 35 & 2 & 11 & 7 \\
\hline HDS2 & 60 & 4.8 & 13 & 9 \\
\hline \multirow[t]{4}{*}{ HDS3 } & 75 & 6 & 15 & 9 \\
\hline & \multicolumn{4}{|c|}{ Case 3: Low $\mathrm{H}_{2}$ demand } \\
\hline & $\mathrm{k}_{\mathrm{H} 2 \mathrm{HC}}$ & $\mathrm{k}_{\text {LIGHC }}$ & $\mathrm{k}_{\mathrm{GHC}}^{\mathrm{s}}$ & $\mathrm{k}_{\mathrm{H} 2 \mathrm{HC}}^{\mathrm{s}}$ \\
\hline & $\mathrm{Nm}^{3} / \mathrm{m}^{3}$ & $\mathrm{Nm}^{3} / \mathrm{m}^{3}$ & $\mathrm{Nm}^{3} / \mathrm{m}^{3}$ & $\mathrm{Nm}^{3} / \mathrm{m}^{3}$ \\
\hline HDS1 & 25 & 1 & 8 & 4 \\
\hline HDS2 & 50 & 4 & 10 & 6 \\
\hline HDS3 & 63 & 5 & 13 & 8 \\
\hline
\end{tabular}
are shown in Figure 3.

\begin{tabular}{||l|l|}
\hline GENERAL STATISTICS \\
\hline INFO & $\#$ \\
\hline \hline Number of equations: & 629 \\
\hline Number of boxes (coupled subsystems of equations): & 2 \\
\hline Number of linear boxes: & 1 \\
\hline Number of nonlinear boxes: & 1 \\
\hline Number of input DATA: & 22 \\
\hline Number of input BOUNDARY: & 47 \\
\hline Number of output EXPLICIT: & 611 \\
\hline Number of output DYNAMIC/DERIVATIVE: & 12 \\
\hline Number of output ALGEBRAIC: & 6 \\
\hline Size of Jacobian matrix (DYNAMIC+ALGEBRAIC): & $18 \times 18$ \\
\hline Sparsity factor in Jacobian matrix (\% of zeros): & 62.962962962962962 \\
\hline Default integration method: & DASSL \\
\hline
\end{tabular}

Figure 3: General statistics of the system. Source: $\operatorname{PROOSIS}^{\circledR}[4]$.

\subsection{CASES STUDIED}

Two state transitions from a baseline case (case1) were simulated: high $\mathrm{H}_{2}$ demand case (case2) and low $\mathrm{H}_{2}$ demand case (case 3 ). Process conditions of cases 1-3 are shown in Table 2 .

Table 2: Cases process conditions. 


\begin{tabular}{|l|l|l|l|}
\hline \multirow{2}{*}{} & \multicolumn{4}{l}{ HC conditions } \\
\cline { 2 - 4 } & $\mathrm{F}_{\mathrm{HC}}$ & $\rho_{\mathrm{HC}}$ & $\mathrm{mw}_{\mathrm{HC}}$ \\
\cline { 2 - 4 } & $\mathrm{m}^{3} / \mathrm{h}$ & $\mathrm{kg} / \mathrm{m}^{3}$ & $\mathrm{~kg} / \mathrm{kmol}$ \\
\hline HDS1 & & & \\
\hline $\mathrm{HC} 1$ & 150 & 800 & 150 \\
\hline HDS2 & & & \\
\hline $\mathrm{HC} 1$ & 130 & 800 & 150 \\
\hline $\mathrm{HC} 2$ & 30 & 850 & 170 \\
\hline HDS3 & & & \\
\hline $\mathrm{HC} 1$ & 105 & 800 & 150 \\
\hline $\mathrm{HC} 2$ & 45 & 850 & 170 \\
\hline
\end{tabular}

Conversely with reaction and solubility coefficients, network flowrates were fixed (i.e.: set as boundaries) and are shown in Table 3. Therefore, system responses were deemed entirely due to $\mathrm{HC}$ properties change rather than operating conditions, such as: feed flowrates, gas purge, etc.

Table 3: Fixed process conditions of the cases studied.

\begin{tabular}{|l|l|l|l|l|}
\hline Boundary & Units & HDS1 & HDS2 & HDS3 \\
\hline MU1.F (from LPH) & $\mathrm{km}^{3} / \mathrm{h}$ & 3.0 & 4.0 & 1.0 \\
\hline RC1.F (recycle) & $\mathrm{km}^{3} / \mathrm{h}$ & 70 & 70 & 70 \\
\hline PG.F (purge to LPH) & $\mathrm{km}^{3} / \mathrm{h}$ & 3.0 & 5.0 & 2.0 \\
\hline Q1.F (Quench 1) & $\mathrm{m}^{3} / \mathrm{h}$ & & 1.0 & 1.0 \\
\hline Q2.F (Quench 2) & $\mathrm{m}^{3} / \mathrm{h}$ & & 1.0 & 1.0 \\
\hline Z.F (PERM inlet) & $\mathrm{km}^{3} / \mathrm{h}$ & & & 9.0 \\
\hline Z.PG (PERM purge) & $\mathrm{km}^{3} / \mathrm{h}$ & & & 2.0 \\
\hline
\end{tabular}

\subsection{SIMULATION}

The simulation experiment consisted in running the network at: baseline conditions first, then case 2 and case 3 . The sequence is shown in Table 4.

Table 4: Simulation sequence

\begin{tabular}{|l|l|l|}
\hline Case & Start time (h) & End time (h) \\
\hline 1 & 0 & 3 \\
\hline 2 & 3 & 8 \\
\hline 1 & 8 & 14 \\
\hline 3 & 14 & 20 \\
\hline 1 & 20 & 24 \\
\hline
\end{tabular}

\section{RESULTS}

\subsection{Global mass balance}

The mass balance of the network was divided into four terms for ease of understanding.
The first term is the $\mathrm{H}_{2}$ consumption occurring in reactors due to chemical demand of $\mathrm{H}_{2}$ (see Figure 4).

The second is $\mathrm{H}_{2}$ from outside being fed to the network (source) and $\mathrm{H}_{2}$ purged to $\mathrm{FG}$ header. This term is shown in Figure 5.

Similarly, two additional terms referring to LIG fed to the network and purged to FG complete the global mass balance. Figures 6-7 show LIG flow rates for the global balance.

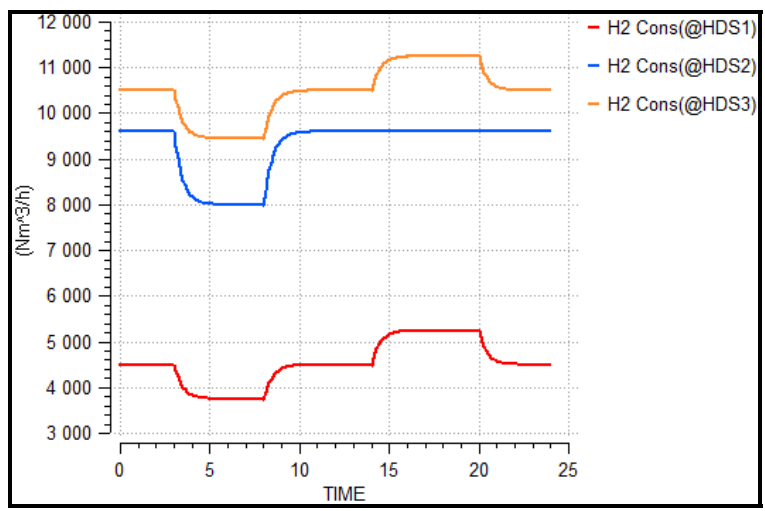

Figure 4: $\mathrm{H}_{2}$ consumption in reactors.

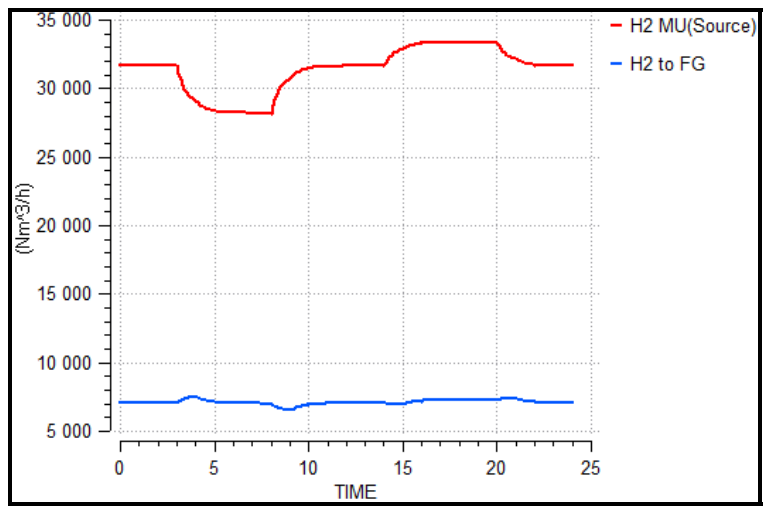

Figure 5: Network $\mathrm{H}_{2}$ in make-up and purge to $\mathrm{FG}$.

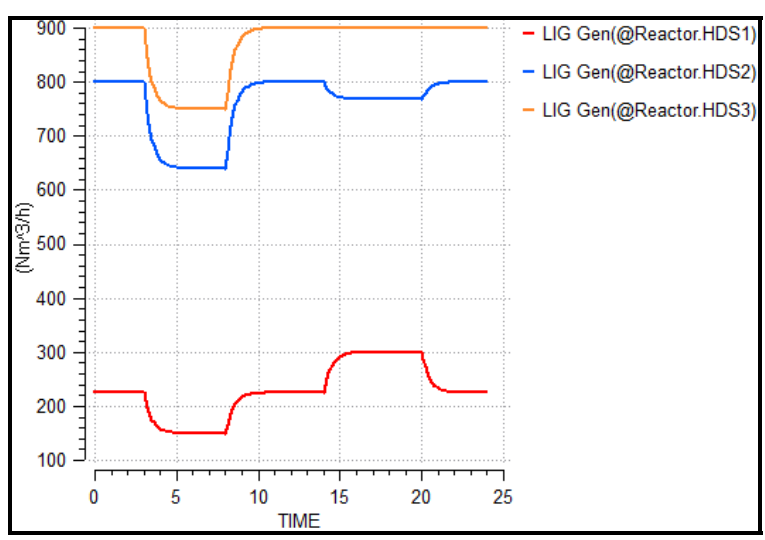

Figure 6: LIG generated in reactors. 


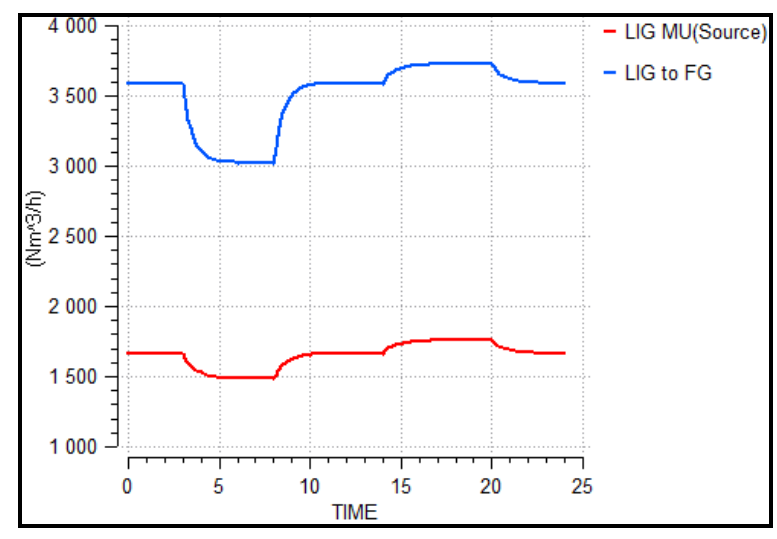

Figure 7: Network LIG in make-up and purge to FG.

\subsection{Solubility coefficients in separation drums}

Gas and $\mathrm{H}_{2}$ solubility coefficients are shown in Figure 8.

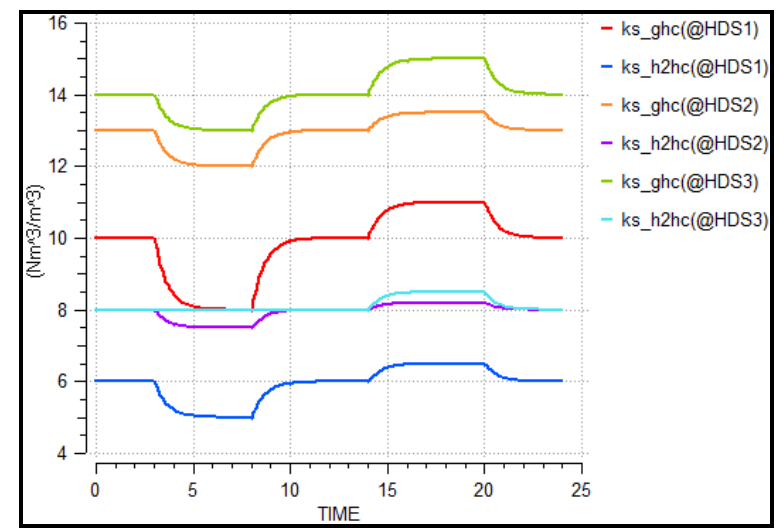

Figure 8: Gas and $\mathrm{H}_{2}$ solubility in $\mathrm{HC}$ at separation drums.

\subsection{Hydrogen purity}

$\mathrm{H}_{2}$ purity is of key importance in desulphurisation processes, especially to maximise catalyst lifecycle $[2,12-13]$. Therefore, is important to control $\mathrm{H}_{2}$ purity in the network. Figures $9-10$ show $\mathrm{H}_{2}$ purity in the network and its values in reactors.

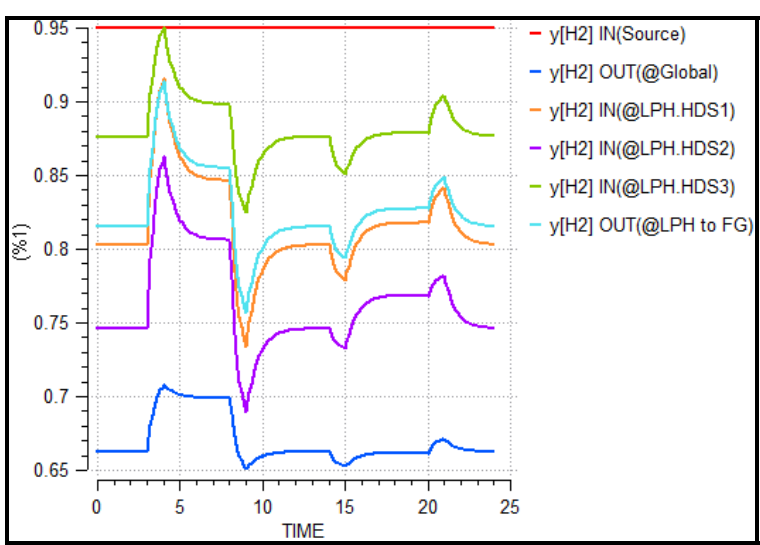

Figure 9: Network $\mathrm{H}_{2}$ purities. $\mathrm{H}_{2}$ purities of: source, purge to FG, LPH inflows and outflow.

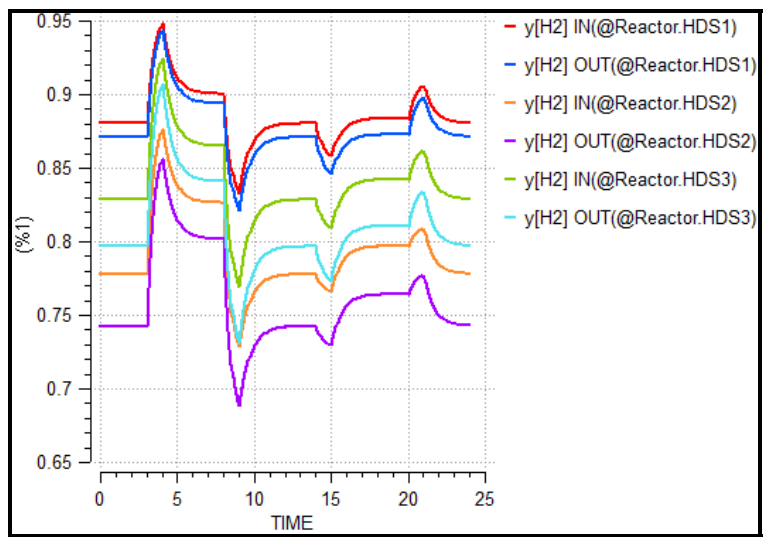

Figure 10: Reactors' $\mathrm{H}_{2}$ purities.

\section{DISCUSSION}

It is seen how $\mathrm{H} 2_{\mathrm{CON}}$ and $\mathrm{LIG}_{\mathrm{GEN}}$ affect $\mathrm{H}_{2}$ make-up from the source (Figures 4-5), since the network closes its global mass balance with the make-up gas. Therefore, transitions from case1-2 and case 3-2 imply diminutions of make-up flow to the network. The opposite happens with transitions from case2-1 and case1-3. However, $\mathrm{H}_{2}$ purity $\left(\mathrm{y}\left[\mathrm{H}_{2}\right]\right)$ within the network changes in the opposite direction (see Figure 9) due to gas and $\mathrm{H}_{2}$ solubility dependence $\left(\mathrm{k}_{\mathrm{GHC}}^{\mathrm{s}}\right.$ and $\mathrm{k}_{\mathrm{H} 2 \mathrm{HC}}^{\mathrm{s}}$, equations 9-10), whose changes are seen in Figure 8. In fact, separators hold responsibility for recycle gas composition in each plant, and consequently within the network. Their influence is due to equations 9-10 which determine the separation in terms of composition and flow rates applying the model proposed by Gomez (2016) [6]. The same response is seen in LIGs, although at different rates (see Figures 6-7). An analogous reasoning explains this behaviour.

A similar analysis can be applied to gas headers, from which LPH and FGH are of particular interest. This is because, the former works as a gas recycle 
sink, receiving plants' LPH purges and providing low purity make-up back into the plants (MU1 inflow and PG_LPH outflow, see Figure 3). In the LPH the FG purge to the FGH takes care of the pressure control of the header, closing its mass balance against the FGH. Since three inflows to LPH are boundaries (purges to LPH) and three outflows are boundaries as well (MU1 to HDS1-3), LPH outflow to FGH is fixed by the mass balance in $3000 \mathrm{Nm}^{3} / \mathrm{h}$ (expressed in volume in equation 1). In addition, FGH receives plants' purges to FG and from LPH, and again, its pressure control is achieved by purging gas off the network as shown in Figure 11. See Figure 1 for LPH and FGH inflows and outflows diagrams within the network. In overall, LPH gas is a component of actual make-up and FGH outflow is the network's purge, usually to flare header.

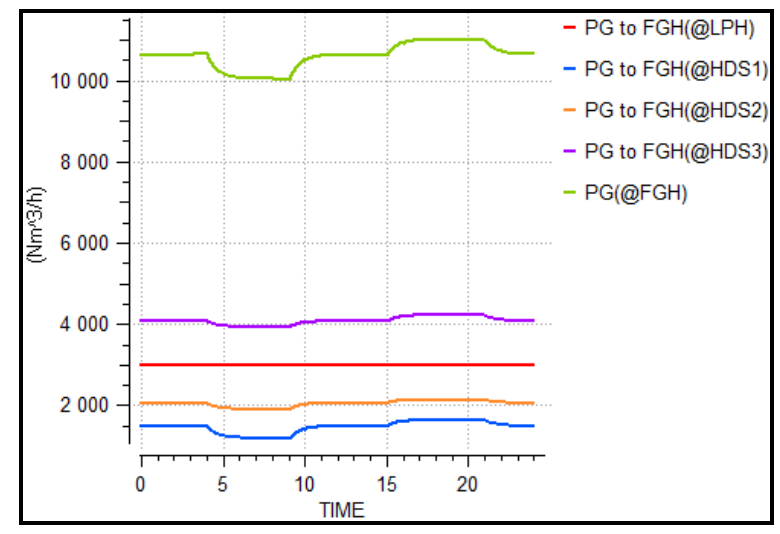

Figure 11: Fuel gas header inflows (PG to FGH) and purge (PG).

$\mathrm{H}_{2}$ purity in the plants show significant dependence with reactors' specific consumptions (i.e.: $\mathrm{k}_{\mathrm{H} 2 \mathrm{HC}}$ and $\left.\mathrm{k}_{\mathrm{LIGHC}}\right)$ and their dynamics. In fact, from case $1-2$ an increment of around 20\% is seen for HDS1-2 and around $12 \%$ for HDS3 (Figure 10). Smaller variations are shown in the rest of the transitions. Therefore the simulation predicts and presents clearly the dynamics of $\mathrm{H}_{2}$ purity in all streams (see Figures 9-10), being this an asset for plant operators, production scheduling team. For instance, $\mathrm{H}_{2}$ purity sharp drops and peaks affect negatively scheduling since it may take longer to comply with expected crude processing timetables. Operators will need to smooth down transitions either by feeding lower rates to the units (least likely) or purging more to LPH (most likely). In any case the process will be constrained and will not meet the optimum scheduling unless transition states were known beforehand. In addition, simulation of the network may aid: in debottlenecking (when $\mathrm{H}_{2}$ is scarce), or in undertaking what-if analysis, due to its ease of setting different scenarios. For example, purity affects (Figures 9-10): compressors performance and catalysts lifecycle. Therefore, it may be challenging for compressors to deal with transitions from case 1-2 and back. Using the network simulation this will be predicted and operators will be able to act in consequence. In overall, simulation of the network holds potential use as support tool in any decisionmaking process where prediction of network streams' status is utilised. In this theoretical network is seen that case 1-2 and case2-1 transitions lead to the most extreme $\mathrm{H}_{2}$ purities. Although their steady states do not show extreme values, in the transitions $\mathrm{H}_{2}$ purities reach values that are usually far below minimum required (typical minimum bound: 60\%). Therefore, schedulers and operators can anticipate and consider more realistic transition times and how to mitigate their effects. Similar advantages will be seen when studying different scenarios and how the network is likely to respond.

It is important to highlight the limitations of the model and their extent. The results shown rely on the dynamics of the $\mathrm{H}_{2}$ consumption and LIG generation in the reactors, and gases solubility in the separation drums (equations 3-4, 9-11). Therefore, a proper and specific determination of: $\mathrm{k}_{\mathrm{H} 2 \mathrm{HC}}^{\mathrm{s}}, \mathrm{k}_{\mathrm{GHC}}^{\mathrm{s}}, \mathrm{k}_{\mathrm{H} 2 \mathrm{HC}}, \mathrm{k}_{\mathrm{LIGHC}}$, $\tau_{i}$ would be essential in any actual network case study. In this work only theoretical and sensible values were applied to probe usefulness of the methodology. In addition, the previous parameters are linked to $\mathrm{HC}$ composition in actual processes, especially to the sulphur content. This was not modelled.

\section{CONCLUSIONS}

A first principle refinery hydrogen network that considered empirical first order dynamics on: $\mathrm{H}_{2}$ consumption, LIG generation, and solubility in separation drums, was modelled. The simulation of the three cases studied showed transient properties along the network that differ significantly from steady states, bringing essential information for operation. In particular the simulation presented an effective analysis of network dynamics in a simplified and empirical-based fashion.The gas purities were the most significantly affected variables with up to $10 \%$ difference between transient and steady state responses. This knowledge is useful for: processing schedule development and normal operation. Other potential usage is identified in minimising compressors operation outside their allowed working region.

Further research on real cases of study should be conducted to validate this methodology, and its utility in the decision-making process in actual refinery hydrogen networks. 


\section{Acknowledgements}

Financial support is gratefully acknowledged from the Marie Curie Horizon 2020 EID-ITN project "PROcess NeTwork Optimization for efficient and sustainable operation of Europe's process industries taking machinery condition and process performance into account - PRONTO", Grant agreement No 675215. The authors are grateful to Petronor and its management for supporting this study.

\section{References}

[1] Aho M., Bergman S., Hammarström L., YliOpas K., Pelkola A., Sourander M., (2009) Closed Loop Dynamic Optimization of a Petroleum Refinery Process, IFAC Proceedings Volumes, Volume 42, Issue 2, pp 257-262, ISSN $1474-6670$, http://dx.doi.org/10.3182/20090506-3-SF4003.00048.

[2] Aydin E., Celebi A., Sildir H., Arkun Y., Canan U., Is G., Erdogan M., (2015) Dynamic modeling of an industrial diesel hydroprocessing plant by the method of continuous lumping, Computers \& Chemical Engineering, Volume 82, pp 44-54, ISSN 00981354 ,

http://dx.doi.org/10.1016/j.compchemeng.2015. 06.005 .

[3] Chakrabarty A., Mannan S., Cagin T., (2016) Chapter 6 - Dynamic Simulation, Chaos Theory, and Statistical Analysis in Process Safety, In Multiscale Modeling for Process Safety Applications, Butterworth-Heinemann, Boston, pp 289-308, ISBN 9780123969750, https://doi.org/10.1016/B978-0-12-3969750.00006-1.

[4] EAI (2017) PROOSIS ${ }^{\circledR} 64$ bits ENTERPRISE, Madrid, Spain, Empresarios Agrupados Internacional SA.

[5] Fonseca A., Sá V., Bento H., Tavares M., Pinto G., Gomes L., (2008) Hydrogen distribution network optimization: a refinery case study, Journal of Cleaner Production, Volume 16, Issue 16, pp 1755-1763, ISSN 0959-6526, https://doi.org/10.1016/i.jclepro.2007.11.003.

[6] Gomez E., 2016, A study on modelling, data reconciliation, and optimal operation of hydrogen networks in oil refineries, Doctoral thesis, University of Valladolid, Spain

[7] Jia N., Zhang N., (2011) Multi-component optimisation for refinery hydrogen networks,
Energy, Volume 36, Issue 8, pp 4663-4670, ISSN 0360-5442, http://dx.doi.org/10.1016/j.energy.2011.03.040.

[8] Kumar A., Gautami G., Khanam S., (2010) Hydrogen distribution in the refinery using mathematical modeling, Energy, Volume 35, Issue 9, pp 3763-3772, ISSN 0360-5442, http://dx.doi.org/10.1016/j.energy.2010.05.025.

[9] Moro L., (2009) Optimization in the Petroleum Refining Industry - I The Virtual Refinery, Computer Aided Chemical Engineering, Volume 27, pp 41-46, ISSN 1570-7946, http://dx.doi.org/10.1016/S15707946(09)70227-5.

[10] Liu S., Rong G., (2013) Analysis on Refinery System as a Complex Task-resource Network, Chinese Journal of Chemical Engineering, Volume 21, Issue 3, pp 253-262, ISSN 10049541, $\quad$ http://dx.doi.org/10.1016/S10049541(13)60485-1.

[11] Micheletto S., Carvalho M., Pinto J., (2008) Operational optimization of the utility system of an oil refinery, Computers \& Chemical Engineering, Volume 32, Issue 1, 2008, pp 170185, ISSN 0098-1354, http://dx.doi.org/10.1016/j.compchemeng.2007. 05.013.

[12] Navia D., Sarabia D., Gutiérrez G., Cubillos F., De Prada C., (2014) A comparison between two methods of stochastic optimization for a dynamic hydrogen consuming plant, Computers \& Chemical Engineering, Volume 63, pp 219233, ISSN 0098-1354, http://dx.doi.org/10.1016/j.compchemeng.2014. $\underline{02.004}$.

[13] Sarabia D., de Prada C., Gómez E., Gutierrez G., Cristea S., Sola J., Gonzalez R., (2012) Data reconciliation and optimal management of hydrogen networks in a petrol refinery, Control Engineering Practice, Volume 20, Issue 4, pp 343-354, ISSN 0967-0661, https://doi.org/10.1016/j.conengprac.2011.06.00 $\underline{9}$

[14] Pitty S., Li W., Adhitya A., Srinivasan R., Karimi I., (2008) Decision support for integrated refinery supply chains, Computers \& Chemical Engineering, Volume 32, Issue 11, pp 2767-2786, ISSN 0098-1354, http://dx.doi.org/10.1016/j.compchemeng.2007. 11.006 . 
[15] Tran M., Varvarezos D., Nasir M., (2005) The importance of first-principles, model-based steady-state gain calculations in model predictive control - a refinery case study, Control Engineering Practice, Volume 13, Issue 11, pp 1369-1382, ISSN 0967-0661, https://doi.org/10.1016/j.conengprac.2004.11.01 $\underline{5}$.

[16] Zhao H., Feng Y., Dong X., Rong G., (2014) Integration Optimization of Production and Utility System for Refinery-wide Planning, IFAC Proceedings Volumes, Volume 47, Issue 3 , pp 9599-9604, ISSN 1474-6670, http://dx.doi.org/10.3182/20140824-6-ZA1003.02128 . 